\title{
Wolle, Stefan, Die heile Welt der Diktatur. Alltag und Herrschaft in der DDR 1971-1989
}

\section{Emmanuel Droit}

\section{OpenEdition}

\section{Journals}

Édition électronique

URL : http://journals.openedition.org/ifha/6553

DOI : $10.4000 /$ ifha. 6553

ISSN : 2198-8943

\section{Éditeur}

IFRA - Institut franco-allemand (sciences historiques et sociales)

Référence électronique

Emmanuel Droit, « Wolle, Stefan, Die heile Welt der Diktatur. Alltag und Herrschaft in der DDR 1971-1989», Revue de I'IFHA [En ligne], Date de recension, mis en ligne le 01 janvier 2012, consulté le 22 septembre 2020. URL : http://journals.openedition.org/ifha/6553 ; DOI : https://doi.org/10.4000/ifha.6553

Ce document a été généré automatiquement le 22 septembre 2020

(CIFHA 


\section{Wolle, Stefan, Die heile Welt der Diktatur. Alltag und Herrschaft in der DDR 1971-1989}

\section{Emmanuel Droit}

1 De par ses origines est-allemandes, sa trajectoire existentielle (il a été exclu de l'université Humboldt en 1972 pour raisons politiques) et son engagement citoyen au moment de l'effondrement de la RDA (notamment au sein du comité pour la dissolution du Ministère pour la Sécurité de l'État, la Stasi), St.W. est une figure importante du champ des recherches historiques sur la RDA. Les travaux qu'il a publiés au cours des années 1990 ont contribué, notamment par leurs titres (« Untergang auf Raten », « Die heile Welt der Diktatur ») à fixer une image de la RDA auprès du grand public.

2 Paru pour la première fois en 1998 dans un contexte politique et historiographique marqué par la dichotomie entre une histoire politique « dure » (centrée notamment sur la politique répression de la dictature du SED) et une histoire sociale « molle », le livre de St.W. fait l'objet d'une nouvelle édition actualisée en lien avec le vingtième anniversaire de la chute du Mur de Berlin. Depuis l'effondrement de la « seconde dictature allemande » et la " révolution archivistique » du début des années 1990, la RDA est devenue un champ historiographie en pleine expansion pris en charge essentiellement par des Allemands mais également par des chercheurs anglais (Fulbrook, Ross), américains (Port, Rubin) et français (Kott).

3 Le lecteur est donc en droit d'attendre de cette nouvelle version la prise en compte des progrès effectués par l'historiographie sur la RDA et notamment tous les apports de l'histoire sociale du politique qu'incarne un historien comme Thomas Lindenberger. L'attente est d'autant plus légitime que le titre même de l'ouvrage de St.W. est une réflexion à penser les rapports entre la domination politique et la vie quotidienne.

4 À la lecture de cette version actualisée, on a le sentiment de lire un ouvrage dépassé sur le plan historiographique. Même s'il constitue une somme factuelle intéressante, de surcroît plaisante à lire (notamment en raison de l'usage modéré mais pertinent de blagues qui se disaient à l'époque de l'État-SED), cette synthèse manque tout d'abord 
dans son architecture de rigueur. Après un détour par les relations internationales, l'auteur aborde le plus souvent sans lien les structures du pouvoir, la question de l'espace public, de la société et de l'économie et enfin du quotidien. Ensuite, il est surprenant de prétendre écrire une histoire des rapports entre domination politique et quotidien sans accorder une attention particulière aux mondes de l'entreprise, élément structurant de la vie des Allemands de l'Est de par ses fonctions multiples (lieu de travail, de redistribution des ressources sociales, de formation idéologique,...). Enfin, ce livre illustre un danger souligné par Jürgen Kocka dès 2003, à savoir celui de " provincialiser " l'histoire de la RDA. Les recherches récentes, celles développées notamment par le ZZF de Potsdam, cherchent à réinscrire la RDA dans un cadre géographique plus large : que ce soit en la comparant avec les pays du Bloc de l'Est ou avec les pays occidentaux.

5 Au final, si cet ouvrage avait une certaine pertinence à la fin des années 1990, il l'a aujourd'hui perdue, faute d'avoir su intégrer les progrès les plus marquants de la recherche sur la RDA.

6 Emmanuel Droit (université de Potsdam) 